\title{
Information and communication technologies in Finnish education
}

\author{
Elaborate strategies and the rugged reality
}

\author{
Matti Sinko and Ella Kiesi \\ Ministry of Education, P.O.Box 293,FIN-00171 Helsinki, Finland. matti.sinko@minedu.fi \\ National Board of Education Helsinki, Finland.
}

Key words: information and communication technologies, use, national policies, primary education, secondary education, teacher in-service training, electronic learning materials, lifelong learning

\begin{abstract}
This article is based on the ComNEd presentation given by Matti Sinko together with Ella Kiesi. It reports findings from recent national research funded by the Finnish National Fund for Research and Development, Sitra. Generally, the findings are positive. Schools are generally well-equipped with the technical infrastructure to support pedagogically meaningful uses of information and communication technologies. Most teachers and students have indicated their willingness to use ICT to a greater extent within constructivist paradigms such as collaborative learning and genuine problem solving. Information and communication technologies are integrated into the curriculum more often in studying foreign and mother tongue languages and in information technology studies. Factors which have prevented more efficient use of ICT are teachers' confidence in their skill levels, in-service training which provides both pedagogical and technical support, and a paucity of electronic learning materials. Suggestions for future improvements are made.
\end{abstract}

\section{BACKGROUND AND MILESTONES OF THE NATIONAL ICT POLICY DEVELOPMENT}

Information society strategies were first formulated by the Finnish government in 1994 and the first version was updated through a process delegated to the Finnish National Fund for Research and Development, Sitra

\footnotetext{
The original version of this chapter was revised: The copyright line was incorrect. This has been corrected. The Erratum to this chapter is available at DOI: 10.1007/978-0-387-35499-6_29 
producing the report Knowledge, Competitiveness and Quality of Life in 1998.

Parallel to this process corresponding strategic documents were drafted in the area of education and research under the auspices of the Finnish Ministry of Education. The implementation of the first National Information Society Strategy for Education and Research 1995-99 was begun in 1995 and was subjected to the evaluation of ICT in Finnish education initiated by the Finnish Parliament and funded by the Finnish National Fund for Research and Development, Sitra in 1997-1998 (Sinko and Lehtinen, 1999).

The focus of the evaluation was broader than just the implementation of the national strategy and resulted in several reports. Shortly after the publishing of these reports and the delivery of the report Knowledge, Competitiveness and Quality of Life to the prime minister in December 1998, the then-Minister-of-Education Olli-Pekka Heinonen set up a task force to draft the second National Information Society Strategy for Education and Research 2000-2004, which was published in April 1999 and the first copies of the English-language version were disseminated at the ComNEd 99 conference.

Based on these documents, reports and processes I will try to draft in this paper an overall picture of the uptake of and the pedagogical use of information and communication technologies in Finnish education focusing mainly on primary and secondary education but addressing to a certain extent issues of tertiary education and lifelong learning outside formal education establishments.

\section{$1.1 \quad$ The strategy for 1995-1999}

The information society strategy in the area of primary and secondary education was implemented through a programme called Information Society Programme for schools 1995-1999. In its aims it emphasised the provision of basic ICT skills and knowledge to all students and also the perspective of lifelong learning was held important. All schools and libraries were to be provided with access to the Internet by the year 2000. Teacher education was considered to be a first priority. Measures were proposed to stimulate and enhance domestic production of digital learning materials.

\section{METHODS USED IN EVALUATING THE ACTUAL USAGE OF ICT IN EDUCATION}

The evaluation was grounded in the fairly extensive review of reviews of research literature of the impact of ICT in education and complemented with various national and comparative international evaluations or assessments 
carried out in recent years. For this evaluation several inquiries were completed by all players in the education field (education officers, headteachers, IT co-ordinators, teachers, and students). A substantial number of case studies of experiments and practices claiming to be innovative were carried out. All this was complemented through administrative data from schools gathered by National Board of Education.

\subsection{Infrastructure}

It may be useful to provide a concise summary of the technical ICT provision of Finnish schools to be able to understand the environment in which teaching and learning in Finnish educational institutions take place at present. The figures indicate, that the access of students and teachers to computing and networking resources is broadly on the same level compared with other highly developed information societies. The student per computer (minimum 386) ratios can be seen in Table 1 and student access to the Internet in Table 2.

Table 1. Computers per School and Students per Computer in 1999

\begin{tabular}{lccc}
\hline Level & PCs/school & \multicolumn{2}{c}{ Students/PC } \\
& & 1999 & $2000^{*}$ \\
\hline Primary & 9 & $12-13$ & 10 \\
Lower secondary & 26 & $11-12$ & 8 \\
Upper secondary & 26 & $9-10$ & 6 \\
Vocational & 82 & $5-6$ & $3-5$ \\
\hline
\end{tabular}

It has to be noted, however, that there are vast deviations from these average figures. One of the most decisive factors seems to be the size of the school: the smaller the school the better equipped it tends to be. Since primary level schools are more often smaller than secondary schools, this explains a slightly surprising finding that primary schools are quite well equipped.

Table 2. ICT provision of the Finnish educational institutions

\begin{tabular}{lc}
\hline \multicolumn{1}{c}{ Students } & Internet connection \\
\hline Primary & 22 \\
Secondary & 21 \\
Vocational & 5 \\
\hline
\end{tabular}

The technical and material infrastructure has developed fairly favourably in recent years. The aim of connecting all schools to the Internet has been nearly achieved. Approximately $90 \%$ of primary schools, $90 \%$ of lower secondary schools, $95 \%$ of upper secondary schools and $100 \%$ of vocational 
schools are now on the Internet. Local area networks have been installed in all schools, except small village schools.

The technical solutions to provide access to Internet can be seen in Figure 1. It shows that the network capacity is sufficient for fairly technically demanding Internet tasks. The majority of schools has a bandwidth of at least $128 \mathrm{kB}$ per second.

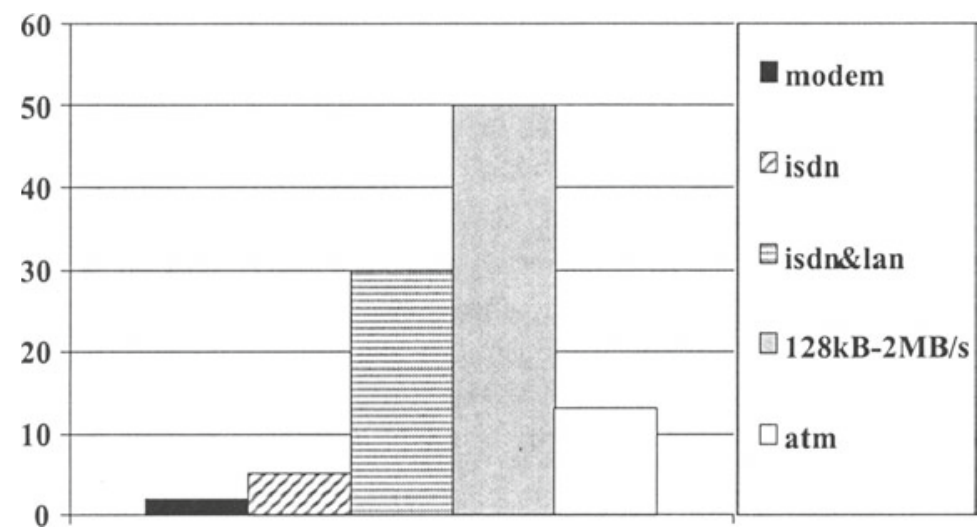

Figure 1. Technical standards of schoolnets

Table 3 summarises the personal access of students and teachers to ICT resources compared with the average figures for all citizens. It shows that the access to ICT of the educational community as a whole has reached levels that provide ample opportunities for utilising these resources for educational purposes. According to Statistics Finland (1997) families with children attending school have higher uptake of personal computers than families on the same economical level with no children attending school. ICT resources available for members of educational communities, libraries provide also an important increment.

Table 3. Personal access to ICT

\begin{tabular}{llccccc}
\hline & & PC & & Internet & \\
& M & F & M & F \\
\hline Teachers & 83 & 83 & 30 & & 30 \\
Tertiary students & 81 & & 67 & 34 & & 19 \\
Secondary students & 90 & & 79 & & 60 & \\
Primary students & 76 & & 74 & & & \\
Homes & & 40 & & & 20 & \\
\hline
\end{tabular}




\subsection{Knowledge and skills of teachers}

According to our study (Sinko and Lehtinen, 1999) only $20 \%$ of teachers feel confident with their present ICT skills and with their pedagogical competence to use ICT. Two thirds of teachers expressed their willingness to get more pedagogical and technical support and training in the use of ICT. Questions were also asked about how teachers perceive new technologies from the viewpoint of emerging constructivist pedagogical paradigm. See Figure 2.

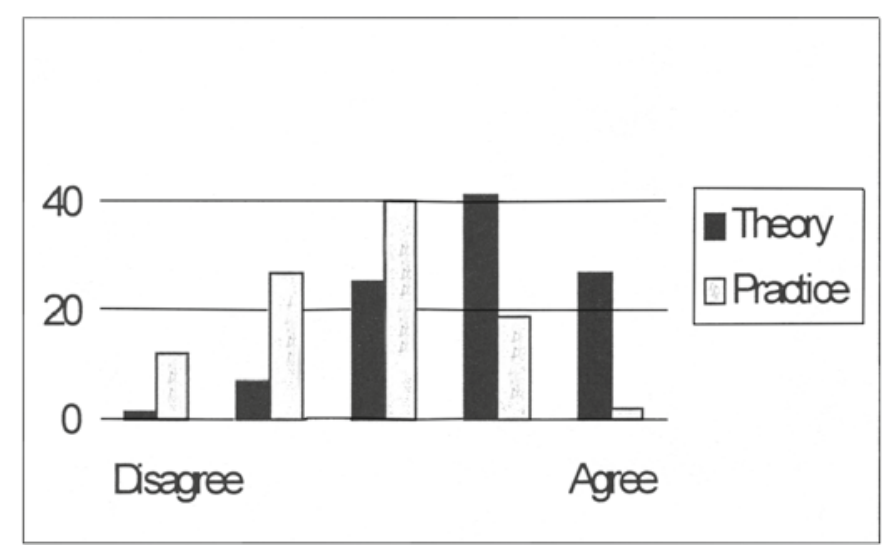

Figure 2. Use of ICT in solving genuine problems according to Finnish teachers

Again two teachers out of three considered ICT very useful in trying to implement these ideas but only few had tried to do so themselves. The results were very similar when answering to the statement "Collaborative learning can be supported by computers". See Figure 3. The reasons for this vast discrepancy can be quite understandable. Teachers may genuinely share the opinion they expressed even though it may be socially acceptable to express that kind of opinion in a survey but lack the resources to implement it. There are in many cases not enough computers available and most teachers also lack necessary skills and competencies to venture into such an activity. 


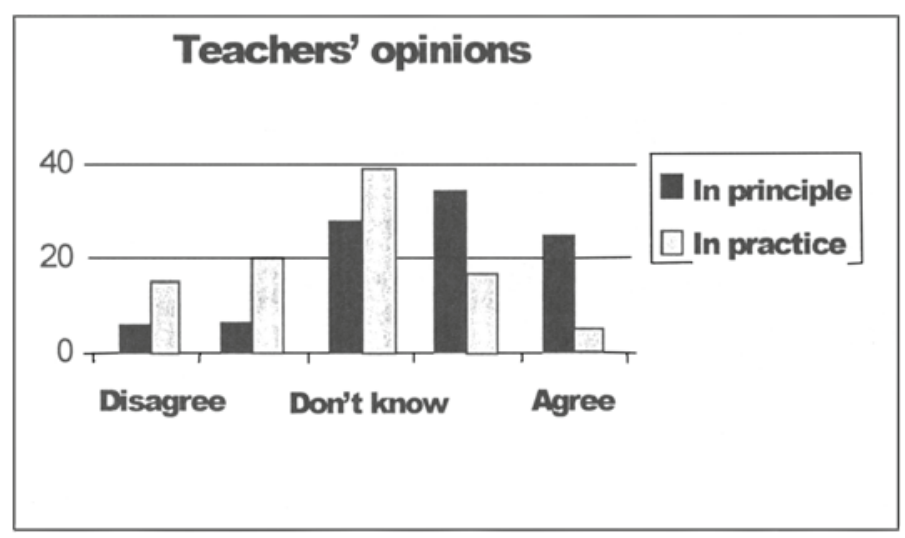

Figure 3. Collaborative learning can be supported by ICT

\subsection{Student achievement}

The ultimate test of the success of educational ICT policy is of course how students can benefit from these investments. We were able to test that only in a limited way. Mainly we had to be content with surveying pupils' and students' opinions of their own skills and competencies. When the skills reported by students themselves were compared with their actual skills, the differences were fairly small. So listening to students' own voices may be useful. When compared with the results of the use reported by teachers of their use, the educational use of ICT can be very concisely presented in the Table 4 and Figure 4.

Table 4. Types of educational use of ICT in Finnish schools

\begin{tabular}{l} 
Types of educational use \\
\hline Word-processing in preparing study reports and research reports \\
Web-browsing for information search \\
Email for communication with peers \\
Graphics \\
Learning about ICT \\
\hline
\end{tabular}

Word-processing has been by far the most common type of use of computers in schools. Now the phenomenal proliferation of the Internet has brought usage of browsing tools up to the second place. The use of ICT for learning about it was not asked but all other evidence shows that it is one of the main rationales behind much of the use of ICT in schools.

When looked at across the curriculum the addition of $\mathrm{C}$ in the acronym of ICT in education becomes justified. ICT seems to be most frequently used in studying languages and mother tongue in addition to IT studies 
itself. Paradoxical, however, is how many students, about $25 \%$ report that ICT is "never" used in IT!

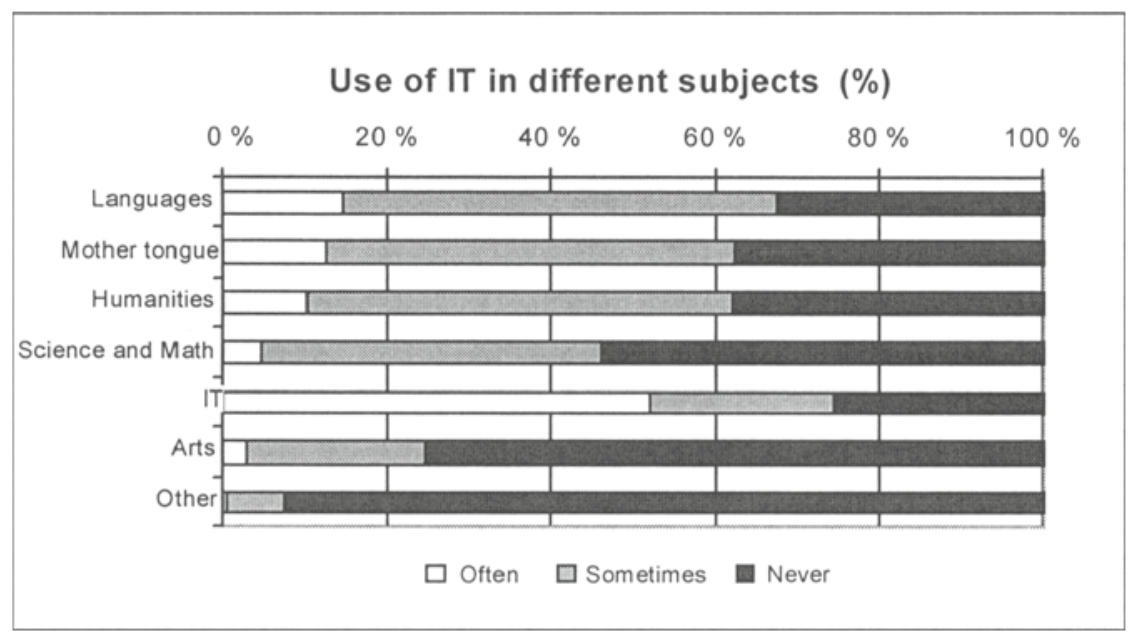

Figure 4. Actual use of ICT in Finnish schools according to students

Students are not too often asked when decisions concerning their working environment are to be changed or reformed. One should - at least in this case. They are eager proponents of increasing the integration of ICT in their learning environments. We should be able to better capitalise on that support readily given by students as shown in Figure 5. And that indeed has happened. Many schools, especially on secondary level are actually dependent on exploiting students' IT expertise. Students maintain computers, servers, and networks, install software, supervise computer labs, support and advise fellow students and teachers, sometimes even train teachers. Some national funding has been allocated to schools for them to be able to acknowledge excelling student achievements by awarding them grants. Sometimes students get also paid for their contribution.

In the national assessment we were able to identify a group of students, about $4 \%$ who could be classified as young IT professionals. They met the criteria that normally are used to identify expertise: they were frequently asked for advice, they provided help, they were paid for their services, they communicated with other professionals in the field. 


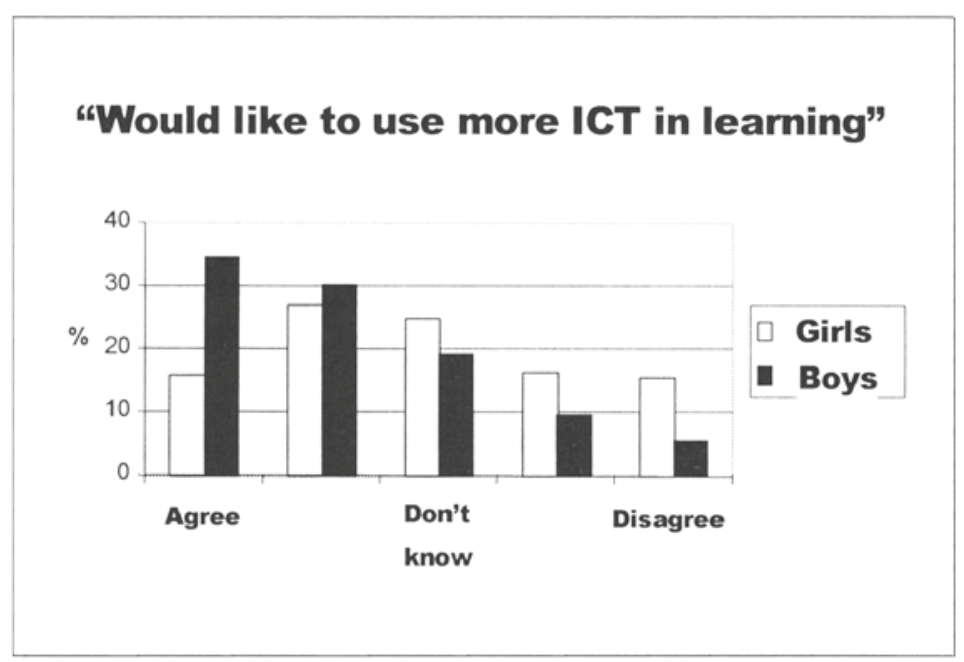

Figure 5. Willingness of students to use ICT in learning

\subsection{Materials and services}

The shortage of relevant electronic materials is a well-known fact throughout the world, and especially so in the countries of small language constituencies like Finland. The commercial providers of traditional educational materials have been quite slow in adopting these new technologies as a means of providing materials for schools and homes. The new media companies on the other hand have lacked resources for long-term investments in development work necessary for a sound and solid basis of materials' production lines. New constellations between old and new businesses take time to be formed. In the meanwhile National Board of Education has supported production of educational multimedia titles thus continuing its role established in supporting the production of so called computer-aided learning (CAL) materials. There has been considerable and sustained efforts to capitalise on the broader Nordic education market through collaboration of Nordic education authorities and companies in design, exchange and dissemination of electronic learning materials. Despite these efforts, the uptake and usage of specific electronic learning materials is extremely low.

\subsection{Curriculum development in schools}

We asked IT co-ordinators and head-teachers, how is determined the use of ICT in schools. The answer was a bit surprising: in almost all of the schools $(96 \%)$ reported that it is up to the teachers themselves to decide 
whether they apply ICT or not in their teaching. This can be considered as a supreme example of professionalism highly appreciated in the Finnish education system. It can, however, be questioned if it is in accordance with the national curriculum guidelines, which do not constitute IT as a compulsory or even a voluntary subject to be offered by schools. The guidelines strongly suggest IT being integrated in all teaching and also to be offered as a specific subject if so desired.

There are specific IT courses in the curriculum in $64 \%$ of the schools. IT skills requirements for all students have been listed in $46 \%$ of the schools. But IT use is defined across the curriculum in $26 \%$ of the schools only. So much remains to be worked out in schools to provide information society skills for students in a systematic and comprehensive way.

\section{SUMMARY OF POSITIVE OUTCOMES}

The state of ICT in Finnish education can be summarised as follows. Throughout the education community attitudes are in general very positive and confident towards implementing new technologies in education. There has been no significant opposition to this intense prioritising of investments in educational technology. Indirectly, one can see passive opposition especially by teachers with strong humanities orientation, who tend to weigh investments in computers and networks against ailing school libraries and cuts in public library acquisitions. Teacher unions have also been reluctant to fully support in-service training schemes which require teachers to invest their own time when at the same time many teachers have been laid off or made redundant, not to mention cuts in fees and teaching hours. Thus it can be recognised a high level of dedication to enhance the use of ICT by all stakeholders on the education scene.

Basic ICT skills have been adopted widely in education establishments. There were no difficulties in identifying plenty of innovative cases in schools on all levels. Many cases indicated also genuine collaboration across the curriculum within a school as well as between two or more schools.

Technical infrastructures are gradually approaching pedagogically appropriate levels. It was also evident that introduction of ICT had clearly been catalysing pedagogical paradigm change in many schools.

Access to ICT resources offered by schools and libraries to students seem to equalise access to and use of ICT provided by homes.

\subsection{To be addressed or improved}

It is clear that on the national level the expenditure for the educational technology has not yet reached sustainable cost levels. On the one hand the 
public money spent is not sufficient to guarantee a pedagogically meaningful technical platform for efficient use of new technology in schools, even though there is enough computers at present to make pedagogical experiments feasible. The most burning shortage concerns especially electronic materials on domestic languages and pedagogical as well as technical support and training for teachers.

There is need to raise the present level of research and development of high-level learning environments. The real challenge for the Finnish education community is to solve the problem of scaling up the results achieved in small-scale well-supported experiments and to disseminate successfully emerging good practices. Furthermore we should not forget the apparent needs to cope with the paramount and constantly growing manyfaceted issues of equality.

The rhetoric of school reforms in general and with regard to the information society in particular seem to lead to a fundamental discrepancy between the aims and the actual outcome of reforms. One reason for this is the difficulty in distinguishing between technical and social innovations. What is technically possible and can be achieved in well-supported and designed small-scale experiments may fail to materialise on a larger scale because of a failure to overcome chasms between innovators and the majority of people inherent in any social innovation. It is easy to get innovators and early adopters to pick up new innovations but it takes much more careful planning and social engineering to make the majority adopt useful innovations if this requires changing old behavioural patterns and investing time and money for benefits not immediately at hand. The history of technical innovations is full of failures to make them socially successful. The short history of educational IT and ICT reforms suggests that we have underestimated this social inertia. This seems to be a universal fact. (Cf. Moore, 1995.)

Unfortunately, our recent evaluation of ICT in Finnish education largely confirms this hypothesis. There are a number of innovative experiments and projects going on all around the country, but it is sometimes difficult to consolidate good practice in the schools participating in the projects - let alone to disseminate the results to other schools. The great challenge is still to accomplish lasting pedagogical changes on a large scale, a challenge which has to be addressed with much more attention in the future than has been the case in the past.

\subsection{New information society strategy for education and research}

A new national strategy for education and research in the information society for the years 2000-2004 has been recently published. It has been 
largely based on the evaluation outlined above. From that perspective it is not surprising that the proliferation of so called information society skills was chosen the first priority to be addressed. Those skills and competencies can best be pursued by raising the skills and competencies of teachers through intensified and improved teacher pre- and in-service education.

More and better ICT and so-called new media professionals are also needed. Investments in physical networks can be justified only if the networks will be effectively used. That means need to develop extensive online education system and services based on one of the best education network infrastructure in the world.

The network capacity will be quite poorly exploited if we fail in enhancing production of electronic learning materials. And as shown earlier the present technical level of education infrastructure needs still strengthening of support structures. All this cannot be achieved through public sector but requires a careful and innovative orchestration of collaboration between public and private sectors.

\section{REFERENCES}

Ministry of Education, Finland. (1995) Education, Training and Research in the Information Society. A National Strategy.

Ministry of Education, Finland. (1999) Education, Training and Research in the Information Society. A National Strategy for 2000-2004.

Moore, G. (1995). Crossing the Chasm. Harper Business, New York.

National Fund for Research and Development (Sitra), Finland. (1998) Knowledge, Competitiveness and Quality of Life.

Sinko, M. and Lehtinen, E. (1999). The Challenges of ICT in Finnish Education. National Fund for Research and Development (Sitra), Finland.

\section{BIOGRAPHIES}

Matti Sinko is Senior Adviser in Ministry of Education, Finland, Manager of the project evaluating ICT in education initiated by Finnish Parliament and funded by Finnish National Fund for Research and Development, Sitra, Member and secretary of the task force responsible for The National Strategy for Education and Research in the Information Society 2000-2004.

Ella Kiesi is the chief technologist of the National Board of Education, who has been in charge of implementing the first national information society strategy for education and research for 1995-1999 for primary and secondary education. Ella is also a member of the task force drafting the National Strategy for Education and Research in the Information Society 2000-2004. 